\title{
Trainability and reversibility in physical fitness among elderly persons taking part in an intervention program
}

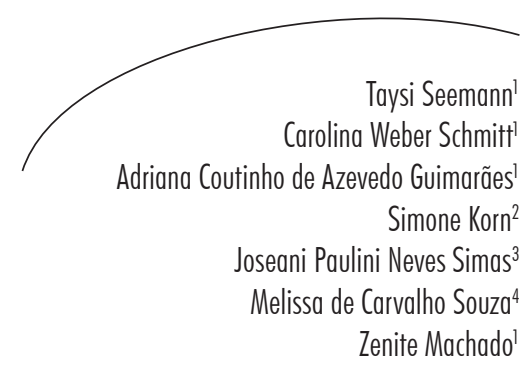

Abstract

Objective: To assess the trainability and reversibility of variables of physical fitness in elderly participants in Active Living Functional Gymnastics. Method: This ex post facto study was composed of 115 elderly women from six functional fitness groups in the Active Living Program in Florianopolis. The Rikli and Jones battery of tests (Chair Stand Test, Arm Curl Test, Chair Sit and Reach Test, Back Scratch Test, 8-Foot Up and Go Test, 6 Minute Walk Test) was used. The intervention period lasted for eight months, and the detraining period took three months. Descriptive and inferential statistics with paired Student t-test and Scheffé post hoc was used. Results: The performance of the age groups differed in agility and aerobic capacity; Trainability was identified in the strength and resistance variables of the lower and upper limbs, and the flexibility of the lower limbs; Detraining was perceived in the strength and resistance of upper limbs, and aerobic capacity. Conclusion: A Functional Gymnastics program produces positive effects on the strength and resistance of the lower and upper limbs, and flexibility of the lower limbs in elderly women. An interruption period lasting three months results in detraining in strength and resistance of the lower limbs and aerobic capacity.

\footnotetext{
Universidade do Estado de Santa Catarina, Departamento de Educação Física do Centro de Ciências da Saúde e do Esporte. Florianópolis, SC, Brasil.

2 Prefeitura Municipal de Florianópolis. Florianópolis, SC, Brasil.

Prefeitura Municipal de São José. São José, SC, Brasil.

4 Universidade do Estado de Santa Catarina, Programa de Pós-graduação em Ciências do Movimento Humano do Centro de Ciências da Saúde e do Esporte. Florianópolis, SC, Brasil.
}

Key words: Aging; Motor Activity; Physical Education and Training. 


\section{INTRODUCTION}

Throughout life, physical fitness and health are related to quality of life. However, it is during old age that this relationship assumes greater importance, as it is in this stage of life that the harm that arises from physical inactivity together with an unhealthy lifestyle becomes more evident, potentially leading to the loss of functional capacity, years of life, or even life itself. ${ }^{1}$ Physical activity can bring benefits for physical fitness, minimizing such losses in physically active people and improving the mental, psychological and social profile of individuals, enhancing the well-being of elderly persons. ${ }^{2}$

Maintaining the ability to care for oneself in an autonomous manner and perform activities of daily living is one way of understanding functional capacity, making it possible to observe if the same is influenced by biological aging and the neglect of the body. ${ }^{3}$ The influence of these variables on functional capacity among the elderly has been described in studies that investigate the trainability of aspects of physical fitness. ${ }^{3}$ Approximately $50 \%$ of physical decline is attributed to biological aging and disuse of the body. ${ }^{4}$ Physical activity programs are available that reduce the negative effects of inactivity on elderly persons by developing and maintaining the physical activities that are considered essential to help improve functionality and the performance of activities of daily living. ${ }^{5}$

The capacity for trainability of the elderly is well documented, given that a decline in physical performance in old age can be delayed through training. ${ }^{6}$ It is important to clarify that the more an individual has already been trained, the more difficult and time consuming it will be to improve, no matter how small, the level of his or her development. ${ }^{6}$ However, merely participating in a physical activity program does not guarantee the maintenance of the physical fitness of elderly persons, due to the pauses/intervals that often take place during training. Depending on the duration of these pauses, reversibility may occur, or in other words, partial or total loss of the benefits and performance acquired, leading to a reduction in the gains attributed to the practice of physical activity through long term training. ${ }^{7,8}$

In a study of 74 elderly women, gains in agility, flexibility, aerobic capacity, strength and resistance were significant after a period of water aerobic activities. ${ }^{9}$ However, after an interruption in training, there were no significant losses in strength, aerobic capacity and flexibility, while there was a significant improvement in agility performance following a break in activities. ${ }^{10}$

Considering the above, a study was designed that had the aim of analyzing the trainability and reversibility of variables of physical fitness in elderly persons who took part in an eight month functional fitness training program and the possible reduction in performance after an interruption for three months. This form of training consisted of exercises with changes in speed, varying amplitudes, changes in direction and different environments, without the use of equipment, aimed at training specific abilities, and was chosen because its effects on the physical fitness of elderly persons have been little investigated to date.

\section{METHOD}

A correlational expost facto study was performed of elderly participants of the Programa Viver Ativo (Active Living Program) in the city of Florianopolis. This program offers a functional fitness training program of 15 exercise groups, with three sessions per week and each session lasting 60 minutes. The sessions were administered by students from the Physical Education degree course, from the fifth period onwards. According to the Viver Ativo program, functional fitness is a form of exercise that involves the performance of exercises of the strength and resistance of members, flexibility, agility and aerobic resistance, using only a person's own body, and dispensing with equipment. The selected elderly persons did not participate in other forms of physical activity, taking part only in the functional fitness classes offered by the Viver Ativo program. 
The sample of this study was non-probabilistic and intentional, comprising 115 elderly participants of six functional fitness groups from the Viver Ativo Program of Florianopolis, as these were the individuals attended during the period of study of the database.

The results of the components of physical fitness of the elderly persons were compared during the period of activities of the program (pre-test and post-test 1 ) and following the return of the individuals to the program following their interval period (post-test 2). This program offers a functional training module aimed at the development of flexibility, strength, agility and balance, with a frequency of three classes per week, and each session lasting 60 minutes. Monitoring involved annual evaluations, in the months of March (beginning of activities) and November (before the end of activities), performed by Physical Education professionals, with the aim of analyzing the development of the elderly individuals. For the evaluations, the instrument developed by Rikli \& Jones, ${ }^{11}$ and described below was used.

The instrument used for the collection of data was the test developed by Rikli \& Jones. ${ }^{11}$ Among the variables evaluated by the protocol, the strength and resistance of members, flexibility, agility and aerobic resistance were evaluated, respectively, by the following tests: "stand up and sit down", "arm curl", "chair sit and reach", "back scratch" "chair stand" and "six minute walk". All the tests were repeated under the same conditions in all the periods of data collection.

After access to the database, screening was performed to identify elderly persons who were evaluated in three target steps. For inclusion, the criteria chronological age (greater than or equal to 60 years) and have participated in the three stages of the tests described above, were considered. Moreover, attendance of at least $75 \%$ of the functional fitness classes was required, with a time of practicing the activities of greater than one year. Initially, the gender of the individual was not constituted to be an exclusion factor, however, after matching data, it was found that the number of elderly males was low
(15), complicating the statistical tests. As a result, these individuals were excluded, and the study was restricted to the female gender.

The results of three tests were used: (a) Pre-test: March 2010; (b) Post-test 1: November 2010; (c) Post-test 2: March 2011. The first two assessments were used to verify a possible improvement in the physical fitness variables of the elderly, while the third evaluation verified losses in the physical fitness variables of the elderly women after an interval of three months in the functional fitness sessions. It should be noted that the evaluation of the elderly women was always performed by physical education professionals trained by the program, giving reliability to the data. The results of these evaluations, carried out by professionals connected to the Viver Ativo program, were used in this study.

The present study used a Florianopolis City Council database, which is part of an ongoing program. The intervention was the functional fitness program offered by the council itself. For this reason there was no control group. Of the 648 participants in the functional fitness group maintained by the Viver Ativo program, only those who had provided data in the three evaluations, or in this case 115 elderly women, were included.

An Excel spreadsheet was created to analyze the data, using descriptive statistics (simple and percentage frequency, mean and standard deviation) to synthesize the values. The data was subsequently transferred to the SPSS Windows 20.0 program, in which inferential statistics was performed. To analyze the differences between training phases (intervention) and the reversal of the training, the paired Student's $t$-test, with Scheffé post hoc, was applied, and the index adopted for the analysis was 0.05 .

The present study was approved by the Ethics in Human Research Committee of the Universidade do Estado de Santa Catarina (Santa Catarina State University) (registration $n^{\circ}$ 63431, dated 30/07/2012). All the participants in the study signed a Free and Informed Consent Form. 


\section{RESULTS}

The results of the present study are based on the mean values for the entire elderly group. Table 1 below shows the mean values obtained for each of the evaluations, and Table 2 presents the $p$ values resulting from comparison of the different combinations.

Tables 1 and 2 show that the behavior of the groups varied between the variables. For the variable "agility", evaluated based on the time needed for task compliance, performance improved between the first and the second assessment and declined between the second and the third evaluation, with the third evaluation presenting the worst performance. However, the differences for all these comparisons were not significant.

The variable "strength and stamina of the lower limbs", the number of repetitions was linearly higher from the first to the third evaluation. All comparisons were statistically significant. The difference between the first and second assessment was expected, considering the trainability factor. However, the significant differences between the second and third evaluation and between the first and the third evaluation were unexpected. In terms of "strength and stamina of upper limbs," there was an increase in the number of repetitions between the first and the second evaluation, a reduction in the number of repetitions between the second and the third evaluation and the first and the third assessment, all of which were significantly different $(p<0.001)$.
When analyzing the variable "flexibility," it was found that performance was different for the lower and upper limbs throughout the study. For "flexibility of the lower limbs", the means of the second evaluation were significantly higher than those of the first $(p<0.001)$. The interval period resulted in a decline in performance, although the difference was not significant $(p=0.216)$. In other words the gains achieved were maintained. The comparison between the first and the third evaluation showed that even after an interval the achievements of the intervention are maintained $(p<0.001)$.

In "flexibility of the upper limbs," the means decreased from the first to the second assessment and increased slightly from the second to the third evaluation, with the value in the third evaluation being greater than the first. Significant differences were not observed for these comparisons.

Regarding the variable "aerobic capacity", there was a slight reduction in the number of meters traveled between the first and second assessment, and a significant reduction from the second to the third evaluation. Although there was no significant difference between the first two assessments $(p=0.993)$, there was a decrease in performance in the recess period $(p=0.017)$ between the first and second evaluation, with this period contributing to a significant reduction in performance compared with values obtained before the intervention $(p=0.019)$.

Table 1. Mean values obtained by elderly participants in the study. Florianopolis, SC, 2011.

\begin{tabular}{lccc}
\hline \multicolumn{1}{c}{ Variable } & Evaluation 1 & Evaluation 2 & Evaluation 3 \\
\hline LL Agility & 5.967 & 5.824 & 6.036 \\
Strength and stamina & 15.022 & 15.728 & 16.364 \\
UL Strength and stamina & 18.617 & 19.844 & 17.330 \\
LL Flexibility & -2.996 & 2.496 & 1.278 \\
UL Flexibility & -6.759 & -7.563 & -6.465 \\
Aerobic capacity & 520.93 & 520.89 & 509.10 \\
\hline
\end{tabular}

$\mathrm{LL}=$ lower limbs; $\mathrm{UL}=$ upper limbs. 
Table 2. Differences between means of different evaluations of elderly participants of the study. Florianopolis, SC, 2011.

\begin{tabular}{lccc}
\hline \multicolumn{1}{c}{ Variable } & $\begin{array}{c}\text { Evaluation 1 } \\
\text { Evaluation 2 }\end{array}$ & $\begin{array}{c}\text { Evaluation 2 } \\
\text { Evaluation 3 }\end{array}$ & $\begin{array}{c}\text { Evaluation 1 x } \\
\text { Evaluation 3 }\end{array}$ \\
\hline LL Agility & 0.178 & 0.059 & 0.580 \\
Strength and Stamina & $<0.001$ & $<0.001$ & $<0.001$ \\
UL Strength and stamina & $<0.001$ & $<0.001$ & $<0.001$ \\
LL Flexibility & $<0.001$ & 0.216 & $<0.001$ \\
UL Flexibility & 0.185 & 0.084 & 0.653 \\
Aerobic capacity & 0.993 & 0.017 & 0.019 \\
\hline
\end{tabular}

$\mathrm{LL}=$ lower limbs; $\mathrm{UL}=$ upper limbs.

\section{DISCUSSION}

Trainability was manifested in three of the six variables (strength and stamina of lower limbs, strength and stamina of upper limbs, and flexibility of lower limbs). The other study variables (agility, flexibility of upper limbs and aerobic capacity) did not show significant differences for the trainability effect, and a trend of underperformance was noted in flexibility of upper limbs and aerobic capacity after the intervention.

It was observed that the strength and stamina of the lower limbs of the elderly participants in this study improved over the course of the two evaluations, with significant benefits from a functional fitness program. Similar results were found in a previous study, in which Cardoso et al. ${ }^{12}$ found that the strength of elderly women who participated in water aerobics improved between the first and the second test after 36 sessions, showing the trainability of this variable. In another study, Mayer $\&$ Lopes $^{13}$ and Alves et al. ${ }^{9}$ also found positive results for this variable.

The results of the aforementioned studies may suggest that lower limb strength is a variable the trainability of which is favored by both exercise programs such as aerobics. According to the authors, as well as providing high gains in muscle strength in elderly persons, such activities also serve to improve quality of life and health status and consequently the maintenance of functional independence..$^{14,15}$

The trainability results for the strength and stamina of the upper limbs in the present study were significant, similar to the findings of Mayer \& Lopes, ${ }^{13}$ Alves et al. ${ }^{9}$ and Berlezi et al., ${ }^{16}$ who identified improved muscular strength and stamina in the upper limbs as a result of the implementation of a physical activity program in elderly persons. According to the study, activities involving resistance exercises are most effective for the prevention and recovery of muscle strength, ${ }^{17}$ thus explaining the improvement of this variable following the functional fitness activity performed by the elderly in this study.

The significant improvement in the flexibility of lower limbs between the first and second evaluation is also supported by literature, which provides similar results. ${ }^{9,16,18}$ However, Rebellato et al. ${ }^{19}$ did not find a significant difference in flexibility among 32 elderly persons that confirmed either the benefits of a long term program or a Pilates intervention, in which the pre-test mean was even higher than the post-test,${ }^{13}$ which differs from the results of the present study. These differences may be the result of the variation in the types of intervention. 
In the case of tests in which no significant differences in the trainability effect were observed, the agility results of the present study contradict those obtained by Alves et al.," who found a significant improvement through the application of a 12-week gymnastics program with two sessions per week. The same divergent result was found in a study by Ribeiro et al. ${ }^{20}$ of individuals taking part in health program fitness exercises, using the flexibility battery of tests proposed by the American Alliance for Health, Physical Education, Recreation and Dance (AAHPERD). The result of the present study was similar to that of Mayer \& Lopes, ${ }^{13}$ who, despite identifying an improvement in the time taken to complete the task among the elderly persons, found that the magnitude of the change was not significant. It is notable that the Ribeiro et $\mathrm{al}^{20}$ study was conducted using a recreational physical activity for ten months, and that of Mayer $\&$ Lopes $^{13}$, with a population group taking part in a Pilates program. One possible explanation for the variety of results found in literature could be the heterogeneity of the instruments and interventions.

The decline in performance between the first and the second evaluation in the back scratch test, which evaluates the flexibility of the upper limbs of the elderly persons in the study, differed from the findings of Alves et al., ${ }^{9}$ who analyzed the effect of water aerobics on the physical fitness of elderly persons and found a significant improvement between pre- and post-test results. Contrastingly, Mayer \& Lopes, ${ }^{13}$ despite observing an improvement in mean results between the pre- and post-tests, did not find a significant difference. The divergence of results presented in literature may be explained by the difference in the intervention methods.

In terms of aerobic capacity, the mean distance in meters covered in this study was slightly lower in the second evaluation, although the difference was not significant, a finding mirrored by Rosa et al. ${ }^{10}$ However, Ribeiro et al., ${ }^{20}$ in a similar study, obtained a noticeable improvement between the first and the second evaluation.
As noted, the present study proposed to evaluate six different components of health-related physical fitness. Takeshima et al. ${ }^{21}$ evaluated the effectiveness of six different physical activity programs on 76 elderly persons, and found that different modalities favor different aspects of physical fitness, and that a suitable combination should include aerobic exercises and one of the following modalities: resistance exercises, balance exercises, or Tai Chi Chuan.

In terms of detraining, the possible reversibility of the mean values between the second and third evaluation was analyzed through a break in the proposed physical activity program for elderly persons. The statistical analysis of the differences between the means of the variables studied revealed diverse reactions, with two cases of detraining, two cases in which the result of the third evaluation was more positive than the second, although the difference was not significant, and even two cases in which the result of the third evaluation was more negative, but again, without a significant difference.

In the agility test, which affects the mobility, speed and dynamic balance of elderly persons, there were no significant losses after the third test, although the average obtained in the third assessment was lower than that obtained in the first evaluation. This result agreed with the findings of Ribeiro et al. ${ }^{20}$ whose intervention took the form of 24 fitness sessions and eight weeks of detraining. Another study ${ }^{10}$ which analyzed the influence of interrupting water-based activities on the functional aptitude of the elderly, obtained a contrasting result, in which there was a significant reduction in agility after a 12 week interval.

Lower limb strength and stamina improved significantly even after detraining, in contrast to the findings of Cardoso et al., ${ }^{12}$ who, after 12 weeks of detraining with elderly women participating in water aerobics, found a non-significant reduction of strength in the lower limbs, and Carvalho al., ${ }^{22}$, who confirmed the effect of detraining. Also contradicting the results of the present study, Raso 
et al. ${ }^{23}$ observed a small non-significant reduction in the strength and stamina of the lower limbs after interruption of a free weight program.

The results of the strength and stamina of the upper limbs test verified the detraining effect, indicating the importance of functional fitness to improve this variable for the older group investigated. While the same findings were obtained by Carvalho et al, ${ }^{22}$ these results differed from those of Rosa et al. ${ }^{10}$ and Prado et al. ${ }^{24}$ who noted an improvement in the performance of elderly persons after an interruption of waterbased activities (water aerobics and swimming).

The flexibility of the lower limbs did not display a significant reduction in performance after the suspension of the activities, agreeing with the results of Rebelatto et al., ${ }^{19}$ who evaluated detraining in 32 elderly persons participating in a long term exercise program. Similarly, Ribeiro et al. ${ }^{20}$ and Carvalho et al. ${ }^{22}$ did not find significant results, after a pause in classes of a fitness program and a training program comprised of a range of activities, respectively.

The third back scratch test, which evaluated the flexibility of the upper limbs of the elderly, revealed no performance loss, or in other words, no effects of detraining. Corroborating the results of the present study, Ribeiro et al. ${ }^{20}$ did not observe a significant change in flexibility following a session of fitness training, similar to the findings of Carvalho et al. ${ }^{22}$

In the evaluation of aerobic capacity, the sample showed a significant drop in performance after a detraining period of three months. Ribeiro et al. ${ }^{20}$ also observed a decline in performance of elderly women who had participated in a fitness program. Prado et al. ${ }^{24}$ also verified a detraining effect following a period of interruption in water aerobics and swimming classes. These results differed from those obtained by Rosa et al., ${ }^{10}$ who, in a study with water-based activities, noted an increase in performance after an interruption in training.
The non-reduction of some physical fitness variables of the participants in the study was possibly due to a lack of control of the activities carried out by the elderly persons during the period of interruption of the functional fitness program (detraining). In other words, the volunteers may have performed activities in which these variables were employed, such as carrying bags, weights, walking, shopping, climbing stairs, and other activities.

Based on the results, it was observed that not all the variables that comprised physical fitness, evaluated by the protocols used, displayed an improvement during the training period, which can be considered a limitation of the study, due to the instrument used. A further limitation is the fact that this was an expostfacto study, which used the database of a program already in progress.

\section{CONCLUSION}

Only the strength and stamina of upper limbs, the strength and stamina of the lower limbs, and the flexibility of lower limbs benefited significantly from the program. Aerobic capacity and agility presented a small, but not significant, increase, while the flexibility of upper limbs declined, although not significantly. However, the present study emphasizes the contribution of the practice of physical activity to the physical fitness of the elderly, as many studies have identified an improvement in the overall physical fitness of the elderly, even using different modalities of exercise.

A significant detraining effect was only identified in two of the variables investigated, although a downward trend in performance was also seen in two other categories. Only one variable displayed an improvement in performance. After detraining, it was observed that although the agility and flexibility of upper limbs returned to almost baseline values, the strength and stamina, and the flexibility, of the lower limbs, remained higher than at the start of exercise program. The most critical effect was observed in the strength and 
stamina of the lower limbs, whose values were significantly lower than those presented at the beginning of exercise. These results indicate that the continuation of activities practiced by the elderly is due to the functional fitness program, which aims to improve physical development in a homogeneous and generalized form. As for the increase in the values of some variables after the interval period, concrete conclusions cannot be drawn, given that the other activities carried out by the elderly in this period of interruption are not known.

Therefore, it is suggested that more studies are conducted, focusing on the detraining period and verifying the activities carried out during the pause in the exercise programs, and that the importance of physical training for the elderly is emphasized, not only during such projects, but throughout the year.

\section{REFERENCES}

1. Cardoso AS, Levandoski G, Mazo GZ, Prado APM, Cardoso LS. Comparação do nível de atividade física em relação ao gênero de idosos participantes de grupos de convivência. Rev Bras Ciênc Envelhec Hum 2008;5(1):9-18.

2. Rocha SV, Carneiro LRV, Virtuoso JS Júnior. Exercício físico e saúde em pessoas idosas: qual a relação? Rev Saúde.com 2006;2(1):85-90.

3. Manidi MJ, Michel JP. Atividade física para adultos com mais de 55 anos: quadros clínicos e programas de exercícios. Barueri: Manole; 2001.

4. Prado SD, Sayd JD. A pesquisa sobre o envelhecimento humano no Brasil: pesquisadores, temas e tendências. Ciênc Saúde Coletiva 2004;9(3):763-72.

5. Benedetti TRB, Gonçalves LHT, Mota JAPS. Uma proposta de política pública de atividade física para idosos. Texto Contexto Enferm 2007;16(3):387-98.

6. Penha JCL, Piçarro IC, Barros Neto TL. Evolução da aptidão física na capacidade funcional de mulheres ativas acima de 50 anos de idade de acordo com a idade cronológica, na cidade de Santos. Ciênc Saúde Coletiva 2012;17(1):245-53.

7. Mujika I, Padilla S. Detraining: loss of traininginduced physiological and performance adaptations. Part I: short term insufficient training stimulus. Sports Med 2000;30(2):79-87.

8. Fatouros IG, Kambas A, Katrabasas I, Leontsini D, Chatzinikolaou A, Jamurtas AZ, et al. Resistance training and detraining effects on flexibility performance in the elderly are intensity-dependent. J Strength Cond Res 2006;20(3):634-42.
9. Alves RV, Mota J, Costa MC, Alves JGB. Aptidão física relacionada à saúde de idosos: influência da hidroginástica. Rev Bras Med Esporte 2004;10(1):31-7.

10. Rosa MF, Mazo GZ, Silva AH, Brust C. Efeito do período de interrupção de atividades aquáticas na aptidão funcional de idosas. Rev Bras Cineantropom Desempenho Hum 2008;10(3):237-42.

11. Rikli RE, Jones JC. Functional fitness normative scores for community-resing older adults. J Aging Phys Act 1999;7(2):129-61.

12. Cardoso AS, Mazo GZ, Balbé GP. Níveis de força em mulheres idosas praticantes de hidroginástica: um estudo de dois anos. Motriz 2010;16(1):86-94.

13. Mayer AP, Lopes WA. A influência do método pilates na aptidão física de idosas do município de Guarapuava PR. Rev Polidiscip Eletrônica Fac Guairacá [Internet] 2011[acesso em 18 fev. 2013];3(2):135-137. Disponível em: http://www. revistavoos.com.br

14. Rocha AC, Fernandes MC, Dubas JP, Guedes DP Júnior. Análise comparativa da força muscular entre idosas praticantes de musculação, ginástica localizada e institucionalizada. Fit Perform J 2009;8(1):16-20.

15. Orsatti FL, Dalanesi RC, Maestá N, Náhas EAP, Burini RC. Redução da força muscular está relacionada à perda muscular em mulheres acima de 40 anos. Rev Bras Cineantropom Desempenho Hum 2011;13(1):36-42.

16. Berlezi EM, Rosa PV, Souza ACA, Schneider RH. Comparação antropométrica e do nível de aptidão física de mulheres acima de 60 anos praticantes de atividade física e não praticantes. Rev Bras Geriatr Gerontol 2006;9(3):49-66. 
17. Doherty TJ. Invited Review: Aging and Sarcopenia. J Appl Physiol 2003;95: 1717-27.

18. Aguiar JB, Gurgel LA. Investigação dos efeitos da hidroginástica sobre a qualidade de vida, a força de membros inferiores e flexibilidade de idosas: um estudo no Serviço Social do Comércio. Rev Bras Educ Fís Esp 2009;23(4):335-44.

19. Rebelatto JR, Calvo JI, Orejuela JR, Portillo JC. Influencia de um programa de atividade física de longa duração sobre a forca muscular manual e a flexibilidade corporal de mulheres idosas. Rev Bras Fisioter 2006;10(1):127-32.

20. Ribeiro DP, Mazo GZ, Brust C, Cardoso AS, Silva AH, Benedetti TRB. Programa de ginástica para idosos nos centros de saúde: avaliação da aptidão funcional. Fisioter Mov 2009;22(3):407-17.
21. Takeshima N, Rogers NL, Rogers ME, Islam MM, Koizumi D, Lee S. Functional fitness gain varies in older adults depending on exercise mode. Med Sci Sports Exerc 2007;39(11):2036-43.

22. Carvalho MJ, Marques E, Mota J. Training and detraining effects on functional fitness after a multicomponent training in older women. Gerontology 2009;55(1):41-8.

23. Raso V, Matsudo SMM, Matsudo VKR. A força muscular de mulheres idosas decresce principalmente após oito semanas de interrupção de um programa de exercícios com pesos livres. Rev Bras Med Esporte 2001;7(6):177-86.

24. Prado APM, Mazo GZ, Cardoso AS, Balbé GP. Aptidão funcional de idosos praticantes de exercícios físicos: a influência do período de interrupção. Pensar Prát 2011;14(3):1-14. 